\title{
Conservation and Management of Ornamental Fish Resources of North East India
}

\author{
Biswas SP ${ }^{1 *}$, Santosh Kumar Singh $\mathbf{A}^{1}$ and Das $\mathbf{J N}^{2}$ \\ ${ }^{1}$ Department of Life Sciences, Dibrugarh University, Assam-786004, India \\ ${ }^{2}$ Department of Zoology, Sibsagar College, Joysagar, Assam-785 665, India
}

\begin{abstract}
The variety of micro-habitats, high diversity of biotic and abiotic components and the suitable climatic condition have made the north-eastern region of India as one of the world's richest repository of ichthyofaunal resources. Being in one of the highest precipitated zone in the world, region is having innumerable streams, lakes and a variety of aquatic habitats. Over 3500 floodplain lakes (beels) are other potential fishery resources in the region and they offer tremendous scope for both culture and capture fisheries. According to one estimate, the region is the home for over 300 fish species ranging from tiny colourful wetland species to gigantic catfishes of the Brahmaputra. About $40 \%$ of them are potential ornamental fish species. Many of them are endemic and as such biopyracy of endemic species is the rule of the day. Further, habitat degradation is also a major concern. An attempt has been made here to examine the current status of exploitation, conservation and management practices of ornamental fishes in the northeast India.
\end{abstract}

Keywords: Ornamental Fish; North-East India; Conservation and Management

\section{Introduction}

Ornamental fish are those small sized, live and colourful fish kept in home or public aquaria or in garden pools for recreation. Mills [1] viewed aquarium fishes as visually exciting objects. This is why; they are also termed as 'live jewels'. In fact, next to birds, aquarium fish are probably the most cheerful living creatures, and in terms of popularity, aquarium keeping has emerged as the second most popular hobby next to photography [2]. With immense popularity of aquarium keeping in public places and households throughout the world, trading of ornamental fish species has become a lucrative business over the years. At present the global annual turnover of ornamental fish trade is about $\$ 10$ billion [3] with a growth rate of $6 \%$ per annum. Although India's contribution to the global ornamental fish trade is meager $(<1 \%)$ at present, but India has a great potential to increase the present level of export to about Rs 150 crores annually.

The entire Northeastern India is endowed with a vast expanse of fresh water habitats mainly flood plain rivers including the mighty Brahmaputra and the adjoining wetlands (locally known as beels). Being in one of the highest precipitated zone in the world, the hilly states of Arunachal, Nagaland, Manipur, Mizoram, Tripura and Meghalaya are having innumerable streams, lakes and a variety of aquatic habitats. The variety of micro-habitats, high diversity of biotic and abiotic components and the suitable climatic condition have made the region as one of the world's richest repository of ichthyofaunal resources. Moreover, floodplain lakes (beels) are other potential fishery resources in the region and they offer tremendous scope for both culture and capture fisheries. Vishwanath [4] reported 296 fish species from N.E. region, which is about one-third of total freshwater fish species, found in Indian waters. However, the aquatic habitats especially in the developing countries have witnessed rapid changes in their aquatic environment that has caused increasingly greater habitat degradation during the past few decades. Like in other parts of the world, the fish habitats of our part of the globe also degraded as a consequence of natural as well as ever increasing human interferences [5]. In view of the importance of the topic, an attempt has been made here to examine the current status of exploitation, conservation and management practices of ornamental fishes in the northeast India.

\section{Characterization of Ornamental Fish and their Exploitation}

The idea about the quality of an ornamental fish may vary from person to person and as such the same species of fish, which has liked by someone, may not attract the others. Since the criteria to designate a fish species to be ornamental are a matter of controversy, it is not surprising to have divergent views among the workers as far as the number of ornamental species of the NE region is concerned. Often trash and even highly esteemed food fishes are described as aquarium fish without a valid reason. Inclusion of food fishes like Ompok spp., Notopterus (Chitala) chitala, Labeo calbasu is as ornamental species require a serious review [6,7]. Similarly, the aesthetic value of certain species like Clarias batrachus, Heteropneustes fossilis, and Monopterus cuchia is also doubtful. Proper evaluation of ornamental status of the available fish species of this region and the nomenclature of certain fish species pose a serious problem [8]. Obviously there is little consensus among the workers about the characterization of ornamental species.

It has now generally been accepted that to be a good competitor in the industry and to sustain a feasible market, the fish species must have a range of attributes that add its suitability as an aquarium fish. An ideal ornamental species should posses attributes like captive survival (including acceptance of artificial diet), attractive colouration pattern, exotically patterned (endemicity), hardiness, peaceful nature, compatible with other species and above all tiny size, so that they can be

*Corresponding author: Biswas SP, Department of Life Sciences, Dibrugarh University, Assam-786004, India, Tel: 09435033479; E-mail: spbsdu@gmail.com

Received November 10, 2014; Accepted December 20, 2014; Published January 22, 2015

Citation: Biswas SP, Santosh Kumar Singh A, Das JN (2015) Conservation and Management of Ornamental Fish Resources of North East India. J Aquac Res Development 6: 310. doi:10.4172/2155-9546.1000310

Copyright: @ 2015 Biswas SP, et al. This is an open-access article distributed under the terms of the Creative Commons Attribution License, which permits unrestricted use, distribution, and reproduction in any medium, provided the original author and source are credited. 
reared in aquarium throughout their life span. However, a dull coloured or ordinary or primitive looking fish like Chaca chaca, Nandus nandus, Badis badis, Sisor rabdophorus and Erethistes pussilus have considerable value as an aquarium fish because of their uncommon appearance make them attractive. Early life stages of certain fish species, especially the juveniles of giant catfishes can be considered as ornamental one.

\section{Ornamental Fish Resources of NE India and their Conservation Status}

Scanning of literature reveals that the northeastern part of India is the home for over 250 fish species ranging from tiny colourful wetland species to gigantic catfishes. Available literature exhibit divergent views as far the number of ornamental species is of this region are concerned. Mahapatra [9] documented 250 species of ornamental fishes from the northeastern states including Sikkim whereas Srivastava [10] reported 115 ornamental fishes from Assam. Srivastava and Singh [11] enlisted 107 fish species as ornamental from Arunachal Pradesh. Similarly, 82 potential ornamental fishes have been recorded from another northeastern state Tripura [12]. However, a close scrutiny of the list of fish reported from N.E. India indicate that a maximum 109 species may be considered as potential ornamental species at least in their early stages of life or during breeding season. Among these, 41 belong to Cyprinidae, 14 belong to Sisoridae, 12 to Cobitidae, 6 each from Balitoridae and Bagridae, 4 each from the family Chandidae, Channidae and Mastacembellidae and the rest of the families having one or two species each.

Colouration of fish is probably the most important factor for attraction. Colouration is an adaptive behaviour, which is either for concealment or for advertisement. Living organism has a tendency to match their body colouration with the surrounding environment so that they cannot be easily detected. Thus, the highly weed infested beels are excellent habitat for many colourful aquarium fishes [13]. Das and Biswas [14] reported 70 species of ornamental fishes from the beels of upper Assam, most of which have considerable commercial value in the domestic as well as overseas market. The most potential ornamental fishes commonly found in such beels are Trichogaster spp., Botia spp., Channa spp., Lepidocephalichthys spp., Badis pp., Nandus nandus, Amblypharyngodon mola and Puntius spp. Majority of the catch recorded from the closed beels being a part of the resident fauna, mostly dominated by the colourful murrels (Channa spp.) and other air breathing forms which can withstand high water temperature, low oxygen level and highly turbid water. Like the beels, a variety of microhabitats are found in the fast flowing streams of Arunachal Pradesh and Nagaland and these distinctive habitats harbour qualitatively rich fauna. The small size, bizarre shape and colouration pattern make the hill stream fishes as good aquarium species. Acanthopthalmus pangia, Balitora brucei, Barilius spp., B. tileo, Batasio tengana, Danio spp, Devario spp., Erethistes pussilus, Garra spp.

As per NBFGR [15], conservation status of freshwater fish diversity was categorized for conservation based on the available data on fish diversity. The assessment of the fishes was done with much attention to the species under threatened categories like endangered (EN) and vulnerable (VU). Among the 120 species, only 58 species have been assessed from the NE region and out of which 20 species are under endangered and 38 species are categorized as vulnerable.

\section{Conservation and Management Strategy for Development of Ornamental Fisheries}

Over 70 species of ornamental fishes has already been described from the Brahmaputra basin, of which at least 20 species can be reared in stagnant without having much technical knowhow. Fish species belonging to the genera Botia, Channa, Lepidocephalus, Somileptes and Trichogaster are well known for their colouration. They are also available in low altitudinal streams. Certain other fishes like Badis, Batasio, Glossogobius, Macrognathus, Mastacembelus, Olyra, Pseudoambassis, Rasbora and Tetraodon can be regarded as potential ornamental fish. The species living in sluggish water and sandy bed habitat are mostly having silvery background with light coloured spots or stripes on lateral part of the body or orange tings on fins. The wetlands with weed infested muddy bottom are serving as refuge for multicoloured species with varying body shapes.

Habitat wise distribution reveals that the hill stream fishes are streamlined, dorso-ventrally flattened, grayish or dark coloured and most of them is bottom feeder, subsist mainly on benthos. One of the major problems with hill stream fish species is that they are very sensitive in terms of water quality and it is very difficult to rear them in captive condition. The maintenance cost to rear hill stream species is often very high and beyond the reach of ordinary people.

Moreover, it has been found that a majority of the fish species, which were once common in the aquatic habitats of the northeast India, is highly depleted from the wild waters. Loss and degradation of habitat and unsustainable fishing as well as unauthorized collection are contributory factors for such depletion in their natural habitats. Recent survey of eight streams of Assam and Arunachal Pradesh indicated a drastic decline of the natural stock of the fish species belonging to genera like Garra, Barilius, Batasio and Danio that were fairly common in the upper Brahmaputra basin even about a decade ago. In addition to that, the current biodiversity status of potential ornamental fish species like Channa barca that was earlier enlisted as data deficient (DD) category [16] should be reviewed. Similarly, emphasis need to be given to review the present status of species like Botia dario, B. rostrata, Chaca chaca, Danio dangila, Rasbora rasbora, Badis badis, Erethistes pussilus, Gagata cenia, etc., which were earlier included in the not evaluated (NE) category. Moreover, a few species can be presumed to have either critically endangered from the wild waters of this region.

Since tropical freshwater ornamental fish has a very high demand in the international market and considering the vast potentiality commercial utilization of aesthetic finishes of the region and their effective conservation, there is a serious need for preparation of a database as well as re-evaluation of the status of aesthetic finfish of the region. The aforesaid problems associated with ornamental fish industry should be redressed at the earliest. For the purpose, a task force should be formed including all stakeholders associated with the industry. It should include experts, researchers, exporters, policy makers, small fish farmers, buyers as well as aquarists. Priority should be given to update the list of ornamental fish fauna of the region in the light of recent information and available data. Moreover, adoption of modern techniques for identification of fish species in order to get rid of taxonomic discrepancies is also suggested. Following strategies are to be adopted for the conservation of natural resources:

\section{Restriction to net usage}

Fishing activity is at its peak during the post-monsoon season and continues up to pre-monsoon except close season of every year (1st April to $15^{\text {th }}$ July). Since monsoon is the breeding season for most of the fishes, it is advisable to ban fishing of native fishes. This can be achieved by restricting the net sizes being used by the fishermen. Only large gill nets should be allowed during monsoon, which are useful to 
catch introduced fishes. Even after the monsoon season, the present restriction on minimum net size should be strictly followed so as to catch only table-sized fishes.

\section{Conservation of spawning grounds}

The breeding areas in major tributaries and wetlands should be demarcated and these areas should be kept under continuous surveillance. Fishing activities should be totally restricted in shallow areas during June to September.

\section{Regulation of migratory fishermen}

The Department should reconsider revenue-oriented approach, while issuing licenses to the fishermen. Licenses should be issued to permanent fishermen residing near the water body, who are solely dependent on the wetland or river for their livelihood. The present status of fisheries in this area, their productivity has been slightly depletion in condition. In order to reduce the fishing pressure, it is advisable to avoid migratory fishermen from fishing.

\section{Strengthening the indigenous fish population}

Taking into account the critical need to conserve fish genetic diversity of the region, rearing and captive breeding protocol for threatened and vulnerable species should be developed without further delay. Even though, there is great demand for the indigenous fishes like Wallago attu, Ompok bimaculatus, Clarias batrachus, Heteropneustes fossilis and Channa species, other commercially valuable fishes are in trace quantities. Other than these fishes, Botia spp., Labeo spp., Mastacembelus armatus, Macrognathus spp., Trichogaster spp. and Mystus spp. have tremendous potential as aquarium fish and their natural stock need to be strengthened either by external input or improving their breeding grounds.

\section{Strict supervision and activation of cooperative society}

The State Fisheries Department of the region lack adequate trained staff for strict supervision of the fishing activity. The manpower should be strengthened through recruitment of skilled and energetic youths. This will provide the much needed scientific approach in term of fisheries management. Another major necessity is to activate the fisheries cooperative societies, which is presently passive. All fishing activities should be carried out through the society. Emphasis should be given to strengthen culture based fishery. Frequent meeting among the fishermen, traders and the departmental staff can strengthened the society. The temporary/ migrant fishermen should be banned.

\section{Proper management of data}

There is no scientific information available about fisheries in lentic and lotic water systems. This severely affects the decision making. Without any statistical data, it is impossible to maintain the healthy fishing activity. Thus, it is of prime importance to maintain at least the data pertaining to yield statistics, species-wise yield, and physicochemical analysis of water at Panchayat level.

\section{Awareness programme for local fishermen}

Fishermen should be properly educated on the importance of fish diversity and aquatic habitats on a regular basis. They should also be provided vocational training for alternative livelihood options during high flood and 'closed season'. This can considerably decrease improper fishing practices by understanding their negative impacts on fish resources.
Lastly, the integration of all these requirements along with the community participation in resource conservation may only secure the conservation and sustainable use of the fish diversity. A strategic plan for habitat and fish and other biodiversity restoration are highlighted as follows:-

1. Raising level of awareness among fisher community regarding fish diversity and their proper utilization.

2. Standardization of breeding technique for locally available ornamental fish species

3. Need for implementation of various Fisheries and Forest Acts in letter and spirit.

4. Popularization of small wetland fish rearing in seasonal water bodies to lessen the pressure on the wild stock.

5. Vocational training for ornamental fish farming for self employment of local youths.

\section{References}

1. Mills M (1990) An Overview of Ornamental Fishes-Fresh and Marine water.

2. Chapman PSJ (1997) Ecology-Principle and Application. Cambridge University Press, UK.

3. Biswas SP, Das JN, Sarkar UK, Lakra WS (2007) Ornamental Fishes of North East India- An Atlas. NBFGR (ICAR) Publication, Lucknow, India.

4. Vishwanath W, Lakra WS, Sarkar UK (2007) Fishes of North East India-An Atlas. NATP-NBFGR, Lucknow, India.

5. Boruah S, Biswas SP (2002) Ecohydrology and Fisheries of the Upper Brahmaputra Basin. The Environmentalist 22: 119-131.

6. Bhattacharjya BK, Choudhury M, Sugunan VV (2003) Ichthyofaunistic resources of Assam with a note on their sustainable utilization. Fish Biodiversity Conservation in North East India. NBFGR, Lucknow, India.

7. Dey SC, Kakati M, Sarma SK (2002) Pre investment feasibility of ornamenta fish trade in NER. Final Report contrived for NEDFI, Guwahati, Assam, India.

8. Sarkar UK, Ponniah AG (2000) Evaluation of North East India fishes for their potential as cultivable, sport and ornamental fishes along with their conservation and endemic status. Fish Biodiversity of North East India.

9. Mahapatra BK, Vinod K, Mandal BK (2004) Ornamental Fish of North Eastern India-Its Distribution and Conservation status. Environ Ecol 22: 674 -683.

10. Srivastava SM, Singh SP, Mahanta PC (2001) Ornamental fish biodiversity of Assam and their conservation status. Integration of Fish Biodiversity, Conservation and Development of Fisheries in North Eastern Region through Community Participation, Shillong.

11. Srivastava SM, Singh SP, Mahanta PC (2002) Ornamental fish biodiversity of Tripura: a need of conservation. Life history traits of freshwater fish population for its utilization in conservation. NBFGR-NATP.

12. Srivastava SM, Singh SP (2002) Intellectual Property Right Regime and Commercially Important Fishes of Arunachal Pradesh. Life history traits of freshwater fish population for its utilization in conservation. NBFGR-NATP.

13. Biswas SP, Boruah S (2000) Fisheries ecology of the North-Eastern Himalaya with special reference to the Brahmaputra River. Ecol Eng 16: 39-50.

14. Das JN, Biswas SP (2005) Present status, diversity and habitat ecology of ornamental fishes in the flood plain lakes of Upper Assam. Bull. Life Sci 11: $32-40$

15. NBFGR (2010) Threatened Freshwater Fishes of India (National Bureau of Fish Genetic Resources, Lucknow.

16. CAMP (1998) Report on the workshop on Conservation Assessment and Management Plans (CAMP) for Freshwater Fishes of India, organized by Zoo outreach and NBFGR. 